Article

\title{
Factors affecting the ability to speak in children with autism spectrum disorders
}

\author{
Siti Maemonah, ${ }^{1}$ Hamidah, ${ }^{2}$ Hari Basuki Notobroto, ${ }^{3}$ Dony Sulystiono, ${ }^{4}$ Luluk Widarti ${ }^{4}$ \\ ${ }^{1}$ Doctoral Program of Public Health, Faculty of Public Health, Universitas Airlangga, Surabaya; ${ }^{2}$ Faculty of \\ Psychology, Universitas Airlangga, Surabaya; ${ }^{3}$ Department of Biostatistics and Population, Faculty of Public \\ Health, Universitas Airlangga, Surabaya; ${ }^{4}$ Lecturer of the Health Polytechnic of the Ministry of Health, \\ Surabaya, Indonesia
}

\begin{abstract}
Background: Communication deficit is one of the characteristics of autism spectrum disorder. Some children with this condition cannot communicate verbally and some have very limited speech skills. This study aims to analyze the factors that affect speaking ability in children with autism, namely age, sex, emotions, attention, and memory.

Design and Methods: This study used a correlational analytical design with a retrospective cohort design. Data were obtained using questionnaires and scales. Furthermore, emotional factors, attention, memory, and age were analyzed for their effects on speaking ability using the Pearson test, while sex was analyzed for their effects on speaking ability using the Eta test.

Results: The results showed that there was a significant effect of attention and age on the speaking ability of children with autism spectrum disorders. Furthermore, it showed that there was a significant effect of emotion on attention.

Conclusions: It was concluded that attention and age affect the speaking ability of children with autism spectrum disorder. Meanwhile, attention in affecting speaking ability is influenced by emotions. Therefore, to improve speaking ability, good emotional management and increased attention is required.
\end{abstract}

\section{Introduction}

Autism spectrum disorder (ASD) is a spectrum of several disorders characterized by: i) deficits in social communication and interactions, ii) limited and repetitive behavior, interests and activities. ${ }^{1}$ It is estimated that the number of children with this condition in the world is 62 out of $10,000 .^{2}$ Meanwhile, in Indonesia, it is estimated that there are 2.4 million people suffering from ASD with the addition of 500 new people/year. ${ }^{3}$ Most patient's parents are more concerned about delays in speech development than other symptoms. Some children with this condition are unable to communicate verbally and some have very limited speech skills. In fact, the proportions of children with ASD who meet the nonverbal, minimal verbal, and verbal criteria are $15 \%, 10 \%$, and
$75 \% .{ }^{4}$ The ability to speak is influenced by several factors, namely biological, cognitive, and emotional factors, age, sex, as well as environmental factors. Meanwhile, Noam Chomsky, one of the most influential linguists of the twentieth century and still dominating theoretical linguistic theory stated that every child has a language acquisition device (LAD), which is the innate ability to speak. Noam asserted that the human brain is biologically programmed to learn language. ${ }^{5}$ Also, twin studies clearly showed that genetic factors play an important role in children's language development. Furthermore, genetic factors account for about $70 \%$ of oral language development disorders. ${ }^{6}$

Jean Piaget, a Swiss psychologist, whose work began to be translated into English in the 1960s stated that language arises from cognitive alterations that change infant sensorimotor processes into formal and logical adult thoughts. ${ }^{7}$ Meanwhile, the ability to communicate with language depends on one's intelligence, which is an intellectual power characterized by complex cognitive achievement, high motivation levels, and self-awareness. Intelligence is a cognitive process. ${ }^{8}$ Furthermore, higher Intelligence Quotient (IQ) scores correlate with better performance in the academic aspects of second language acquisition.

There are four possible relationships between language and emotions. First, between language and emotions there is no direct relationship, but is chained by cognition (cognition conceptualizes emotions and language is a reflection of cognition). Second, there is a direct relationship between language and emotion (verbal speech can be a direct expression of emotion). Third, there is a direct and indirect relationship between language and emotions (language is a conceptualization and expression of emotions). Fourth, language has different relationships with emotions, depending on its type. Anger or fear is often expressed non-verbally, whereas shock is usually expressed verbally. ${ }^{9}$ Also, speech and language skills normally develop with age. The infant's initial speech is uniform prelinguistic speech, regardless of the language used by the caregiver. ${ }^{10}$ Therefore, along with the increasing linguistic complexity, the clarity of speech increases. ${ }^{11}$

The females generally perform language tasks better than males. Furthermore, males receptive and expressive language scores were lower than females. ${ }^{12}$ In addition, Burman et al. showed a greater activation of language areas in females. ${ }^{13}$ Twin

\section{Significance for public health}

Communication deficit is one of the characteristics of autism spectrum disorder. Some children have very limited speech skills; therefore, they will experience challenges in the learning process at school and interactions in the community. Furthermore, support from family, school, and the community is needed to facilitate optimal growth and development in children with this disorder. To support children with this condition, especially in improving their speaking skills, it is necessary to know the factors that affect their speaking ability. Therefore, this paper analyzes the factors associated with speaking ability in children with autism spectrum disorders. 
studies showed that environmental factors play an important role in children's language development. Based on the meta-analysis, it was shown that $30 \%$ of language disorders are caused by environmental factors. ${ }^{6}$ Hayiou-Thomas concluded that the environment has a major effect on children's language skills, which include grammar skills and vocabulary mastery. Genetic factors also play an important role in children's language skills. There is a longitudinal relationship between early speaking skills and language. Children can master language by socially interacting with their environment and through their cognitive development. ${ }^{14}$

Family, especially parents, is the most important factor in children's language development, because the family is the child's closest environment, hence communicative behavior from the family is needed. Also, parenting patterns have been shown to influence children's language development. ${ }^{15,12}$ Verbal communication in individuals with ASD often shows certain characteristics, such as: i) ecolalia, ii) reversal of pronouns, iii) very literal, iv) neologism, v) metaphorical language, vi) repetition of questions, vii) affirmation by repetition, viii) autistic speech style: speech may be too formal, verbose in both vocabulary and grammar, ix) demanding the same verbal scenario, and $\mathrm{x}$ ) poor prosody control. Children with this condition show increased activation in Wernicke's area but decreased activation in Broca's area. Although there is increased activation in Wernicke's area, it indicates a reduction in functional connectivity (less correlation in activity) in the two areas, thus supporting the idea that language function may be less integrated in children with ASD. ${ }^{16}$ This study aims to identify factors that affect speaking ability in children with autism.

\section{Design and Methods}

This study used a correlational analytical design with a retrospective cohort design, namely the form of events observation that have occurred, and aims to find factors related to the cause. The dependent variable is speaking ability, while the independent are: age, sex, emotion, attention, and memory. Also, speaking ability, age, emotion, attention, and memory have an interval data scale, while sex was at nominal scale. Before collecting data, the study protocol was carried out by an ethical test in the Health Research Ethics Committee of the Faculty of Nursing, Airlangga University, Surabaya and passed the review. Furthermore, respondents were determined and given informed consent which contains written explanations about the study via WhatsApp messages. In addition, data collection was carried out by providing a questionnaire via google form from April 16 to August 28, 2020.

The instruments used were: the speaking and communication subscale from the Autism Treatment Evaluation Checklist (ATEC) scale, the modified emotional behavior problem questionnaire from the Indonesian Ministry of Health to measure emotions, the attention subscale from the Swanson, Nolan, and Pelham scale, version IV (SNAP-IV) to measure attention, as well as the Observer Memory Questionnaire-Parent Form (OMQ-PF) adapted to the child's condition to measure memory. Meanwhile, data on age and sex were obtained through a questionnaire, which were in google form. Also, the population were children suffering from ASD with the following inclusion criteria: i) diagnosed with ASD by a doctor or psychologist, ii) there was no hearing and vision loss, iii) age between 5 - 11 years, iv) not accompanied by other diagnoses of children with special needs (down syndrome, learning disabilities, attention and hyperactivity disorders, cerebral palsy, deaf, blind, and other physical disabilities), and v) parents participated in this study. The sample was 55 children, which were obtained by sending informed consent via WhatsApp messages to parents who have children with ASD and registered in the Regional Technical Implementation Unit. The factors of age, emotion, attention, and memory were analyzed for their effects on speaking ability using the Pearson test, while the factors of sex was analyzed for their effects on speaking ability using the Eta test. In addition, the error rate used was 0.05 .

\section{Results and Discussions}

This study was conducted on 55 children with ASD, in which 49 were males and 6 were females (Table 1). The ages were between 5 11 years with the following details: 6 children aged 5 years, 7 aged 6 years, 12 aged 7 years, 9 aged 8 years, 8 aged 9 years, 7 aged 10 years, and 6 aged 11 years. The results showed that the sex of ASD children was mostly male, namely 49 out of 55 (Table 1). This is in accordance with Barman, ${ }^{5}$ who concluded that the most replicated findings are male dominance from ASD. The male: female ASD ratio has been reported as 4.5:1. Also, Pearson test results showed a significant correlation between attention and speaking ability with a significance of 0.000 (Table 2). Meanwhile, the ability of children to speak is the result of a learning process, whether intentional or not. Success in learning is influenced by attention and motivation. Furthermore, attention enhances the perceptual process. Perception will help select and organize important information. Motivation stimulates curiosity. Curiosity will encourage further exploration and stimulate the brain to learn and remember. The learning process is influenced by emotions, which is mediated by attention and motivation. ${ }^{17}$ The results showed that there was a significant correlation between emotion and attention with ASD, and a significance of 0.000 . These results are consistent with the theory of selective attention which explains the general finding that high-intensity emotional information is often prioritized for attention processing. ${ }^{18}$ Several studies have reported that children with ASD have abnormalities in almost all brain structures, but the most consistent abnormalities are in the limbic system, especially the hippocampus and amygdala, as well as the cerebellum. ${ }^{19}$ Disorders of the amygdala and hippocampus, which are the center of

Table 1. Characteristics of respondents.

Characteristics $\quad$ Frequency Percentage
of respondents

Sex

$\begin{array}{lcc}\text { Male } & 49 & 89.1 \\ \text { Female } & 6 & 10.9\end{array}$

\begin{tabular}{ccc} 
Age (y.0) & & \\
5 & 6 & 10.9 \\
6 & 7 & 12,7 \\
7 & 12 & 21,8 \\
8 & 9 & 16,4 \\
9 & 8 & 14,5 \\
10 & 7 & 12,7 \\
11 & 6 & 10.9 \\
\hline
\end{tabular}

Table 2. Correlation test values.

\begin{tabular}{lcc} 
Variable & Pearson Correlation & Sig \\
Age & $0.433(* *)$ & 0.001 \\
Emotions & -0.258 & 0.057 \\
\hline Attention & $-0.515\left(^{* *}\right)$ & 0.000 \\
Memory & 0.039 & 0.777 \\
\hline
\end{tabular}


emotions, cause children with ASD have difficulty controlling emotions, panic, over reactive, irritable, anxious. ${ }^{20}$ Also, the limbic system affects memory, as evidenced by the massive loss of new memory formation in some adult patients with damage to the hippocampus and amygdala. ${ }^{19}$ Lathe concluded that abnormalities in the limbic system are associated with impaired memory, anxiety, social interactions, perception of facial features and emotions, language, sensory deficits, seizures, and repetitive behavior in ASD. ${ }^{20}$ The number of cerebellar purkinje cells in ASD was smaller. In the cerebellar cortex, glutamic acid decarboxylase (GAD) $65 \mathrm{kDa}$ and 67 $\mathrm{kDa}$ decreased, alpha nicotinic receptor subunits decreased while alpha 7 receptor subunits increased, and serotonin concentrations in the dentate nucleus showed improvement. These anatomical and biochemical changes affect the role of the cerebellum in the learning, cognitive, memory, emotional, and motor processes. ${ }^{21}$

The total cortical volume in ASD is about 3\% less than in normal children, and the total surface area is 5\% less than in normal children.22 Also, several areas are significantly thinner in children with ASD aged 4 and 5 years, namely the superior temporal sulcus (STS), inferior frontal gyrus (IFG) pars opercularis, and inferior parietal lobule (IPL). This cortical depletion correlates with social and communication disorders in children with ASD. Also, cortical depletion was observed in areas involved in emotional recognition and social awareness. ${ }^{23}$

The results also showed a significant correlation between age and speaking ability with a significance of 0.001 . Meanwhile, speech and language skills normally develop with age. ${ }^{10}$ The baby's initial speech is uniform prelinguistic, regardless of the language used by the caregiver. This initial greeting is cooing. Cooing is the initial stage of a child issuing a sound as a form of language expression. The sound form that is usually produced at this stage is the vowel phoneme sound. During its development, children can combine several vowels and produce them with sounds that tend to be longer. The longer the child's language skills are more complex, and the speech becomes clearer. Clarity and clarity of speech can be assessed by how much a child's speech can be understood by strangers, without knowing what the child wants to say. Generally, the utterances of children aged 2 and a half can be understood by foreigners, three-quarters of the three-year-old can understand them, and the words of children aged 4 years can be fully understood. ${ }^{11}$ There is a greater mean glial cell density in ASD than in controls in brain regions associated with speech production and processing, namely: Broca's area (Brodmann 44), Wernicke's area (Brodmann 22), and angular gyrus (Brodmann 39). ${ }^{23,24}$

The results showed there was no influence between sex and speaking ability in ASD children (Table 3). These results are not in accordance with previous studies which concluded that the scores of receptive and expressive language in males are lower than in females. These results are not in accordance with previous studies which concluded that the scores of receptive and expressive language in males are lower than females. ${ }^{12}$ This could be due to differences in autism levels of children with ASD being studied. Therefore, the higher the autism level, the more severe the damage to verbal and non-verbal communication skills. The results also showed that there was no effect of memory on the speaking ability of children with ASD. Meanwhile,

Table 3. Eta value.

\begin{tabular}{lc} 
Variables & Values \\
Sex & 0.546 \\
Speaking ability & 0.025 \\
\hline
\end{tabular}

children's achievement in speaking is the result of learning from their environment. ${ }^{6}$ Memory has a very important role in the learning process, and the results showed that there was no influence of memory ability on speaking. This can be caused by disorders in children that affect their speaking ability, including oro-motor disorders which are one of the conditions in ASD children. Page and Boucher (1998) reported that about $80 \%$ of children with ASD have some type of motor damage. ${ }^{25}$ They also reported that all children with motor impairments had oro-motor problems. In addition, they reported that higher rates of motor impairment were associated with lower levels of education and worse language scores. The absence of memory influence on speaking ability in children with ASD can be caused by problems integrating brain function into a coherent concept. Also, some highly functioning children with autism have extraordinary powers at single word processing, while being severely impaired in their ability to process the meaning of complex sentences. Apart from this, genetic factors have a significant influence on speaking ability. ${ }^{26}$

\section{Conclusions}

It was concluded that the factors affecting the speaking ability of children with autism spectrum disorder are attention and age. Furthermore, attention in influencing speaking ability in children with this condition is influenced by emotions.

Correspondence: Hari Basuki Notobroto, Department of Biostatistics and Population, Faculty of Public Health, Universitas Airlangga, Jl. Mulyorejo, Surabaya, Jawa Timur 60115, Indonesia.

Tel. +62.315920948 - Fax: +62.315924618

E-mail: haribasuki.n@fkm.unair.ac.id

Key words: Speaking ability; autism spectrum disorders; attention; emotion.

Acknowledgments: The authors would like to thank the head, deputy head, and all staff at the Regional Technical Implementation Unit for Children with Special Needs in Sidoarjo Regency who have helped a lot in finding the respondents.

Contributions: All authors contributed equally to this article. This study was conducted by $\mathrm{SM}$; $\mathrm{HH}, \mathrm{HB}$, served as supervisors and reviewed the final article; LW, DS, processed and presented the data.

Conflict of interests: The authors declare no potential conflict of interest.

Funding: Universitas Airlangga supported this study.

Ethical Approval: The study protocol was carried out by an ethical test in the Health Research Ethics Committee of the Faculty of Nursing, Airlangga University, Surabaya, Indonesia, and passed the review. Respondents were determined and given informed consent which contained written explanations about the study.

Conference presentation: Part of this study was presented at the $1^{\text {st }}$ International Nursing and Health Sciences Symposium, November $13^{\text {th }}$ to $15^{\text {th }} 2020$, Brawijaya University, Malang, Indonesia.

Received for publication: 14 January 2021.

Accepted for publication: 20 March 2021.

oCopyright: the Author(s), 2021

Licensee PAGEPress, Italy

Journal of Public Health Research 2021;10:2236

doi:10.4081/jphr.2021.2236 


\section{References}

1. American Psychiatric Associaton. Diagnostic and statistical manual of mental disorders, DSM-5, 5th ed. Washington: American Psychiatric Publishing; 2013. Accessed: 2019 Dec 27. Available from: http://displus.sk/DSM/subory/dsm5.pdf

2. Elsabbagh M, Divan G, Koh YJ, et al. Global prevalence of autism and other pervasive developmental disorders. Autism Res 2012;5:160-79.

3. Ministry of Women's Empowerment and Child Protection of the Republic of Indonesia [Internet]. [Hari Peduli Autisme Sedunia: Kenali Gejalanya, Pahami Keadaannya (World autism care day: Recognize the symptoms, understand the conditions)].[in Indonesian]. Ministry of Women's Empowerment and Child Protection. 2018. Accessed: 2019 Dec 27. Available from: https://www.kemenpppa.go.id/index.php/page/ read/31/ 1682/hari-peduli-autisme-sedunia-kenali-gejalanya-pahamikeadaannya

4. Norrelgen F, Fernell E, Eriksson M, et al. Children with autism spectrum disorders who do not develop phrase speech in the preschool years. Autism 2015;19:934-43.

5. Barman B. The linguistic philosophy of Noam Chomsky. Philos Progr. 2012;51:103-22.

6. Stromswold K. Biological and psychosocial factors affect linguistic and cognitive development differently: A twin study. Biol Psychosoc Factors Dev. Accessed: 2020 Jan 27. Available from: https://ruccs.rutgers.edu/images/tech_rpt/tr-82/TR_ StromCogLingGene.pdf

7. Harris CL. Language and cognition. In: The cognitive neuroscience movement. 2009. p. 1-6 Accessed: 2019 Dec 27. Available from: https://www.bu.edu/psych/charris/papers/ Encyclopedia.pdf

8. de Ribaupierre A, Lecerf T. Intelligence and cognitive development: three sides of the same coin. J Intell 2017;5:14.

9. Foolen A. The relevance of emotion for language and linguistics. In: Ad Foolen, Ulrike M. Lüdtke, Timothy P. Racine, Jordan Zlatev, editors. Moving ourselves, moving others: Motion and emotion in intersubjectivity, consciousness and language. J. Benjamins Publishing Co.; 2012. p. 347-68.

10. Coplan J. Normal speech and language development: an overview. Pediatr Rev 1995;16:91-100.

11. Coplan J, Gleason JR. Unclear speech: Recognition and significance of unintelligible speech in preschool children.
Pediatrics 1988;82:447-52.

12. Wesselschmidt RL, Schwartz PH. Chaos, poverty, and parenting: predictors of early language development. Early Child Res Q 2012;27:339-51.

13. Burman DD, Bitan T, Booth JR. Sex differences in neural processing of language among children. Neuropsychologia 2008;46:1349-62.

14. Hayiou-Thomas ME. Genetic and environmental influences on early speech, language and literacy development. J Commun Disord 2008;4:397-408.

15. Aljoundi EK. Language acquisition theories. ResearchGate 2014. Accessed: 2019 Dec 27. Available from: https://www.researchgate.net/publication/299657306

16. Pungello EP, Iruka IU, Dotterer AM, et al. The effects of socioeconomic status, race, and parenting on language development in early childhood. Dev Psychol 2009;45:544-57.

17. Wan CY, Schlaug G. Neural pathways for language in autism: The potential for music-based treatments. Future Neurol 2010;5:797-805.

18. Tyng CM, Amin HU, Saad MNM, et al. The influences of emotion on learning and memory. Front Psychol 2017;8:1-22.

19. Yiend J. The effects of emotion on attention: A review of attentional processing of emotional information. Cogn Emot 2010;24:3-47.

20. Lathe R. Autism, brain, and environment. London: Jessica Kingsley Publishers; 2006.

21. Geller L. Emotional regulation and autism spectrum disorders. Asperger Center for Education and Training. 2005. Available from: http://aspergercenter.com/articles/Emotional-Regulation-and-Autism-Spectrum.pdf

22. Pérez Pouchoulen M, Miquel Salgado-Araujo M, Saft P, et al. [El cerebelo en el autismo].[Article in Spanish]. eNeurobiol 2012;3:3-11.

23. Mensen VT, Wierenga LM, van Dijk S, et al. Development of cortical thickness and surface area in autism spectrum disorder. NeuroImage Clin 2017;13:215-22.

24. Hadjikhani N, Joseph RM, Snyder J, et al. Anatomical differences in the mirror neuron system and social cognition network in autism. Cereb Cortex 2006;16:1276-82.

25. López-Hurtado E, Prieto JJ. A microscopic study of languagerelated cortex in autism. Am J Biochem Biotechnol 2008;4: 130-45.

26. Deshmukh RS. Motor speech characteristics of children with autism. PhD Thesis, Ohio State University; 2012. 